\title{
Research on the Leisure Sports Courses Construction and Development in Applied Undergraduate Colleges and Universities
}

\author{
Huiqiao Duan
}

Wuhan Business University, Wuhan, Hubei Province, China

\begin{abstract}
Keywords: Applied Undergraduate Colleges and Universities, Leisure Sports, Curriculum
\end{abstract} Construction, Curriculum Development

\begin{abstract}
With the progress of society, people's demand for life is getting higher and higher, and high-quality life cannot be separated from a healthy body. Recreational sports advocate entertainment and exercise simultaneously, therefore, it can be said to be a suitable way of a strong body. By contrast, college students have more active thinking, who are easier to accept new things, so the popularity of leisure sports can start from college students. Students can form the correct understanding of leisure sports, and lead other people to understand leisure sports, so as to promote the construction of leisure sports nationwide. This paper begins with the importance of constructing leisure sports in colleges and universities. Based on the phenomena in current college sports teaching, it puts forward some constructive measures for the development of leisure sports in colleges and universities.
\end{abstract}

\section{Introduction}

With the development of society, people pay more attention to their own health. Therefore, sports are more and more popular. However, traditional competitive sports not only take time, but also require professional guidance. Most people do not have this condition. However, leisure sports gradually attract people's attention because of its non-professional and leisure features. University courses easier, many students have more time after class I do not know how arrangements, many students choose to stay in hostels, this is not conducive to their own health. Therefore, the implementation of leisure sports in colleges and universities is the best choice [1]. The construction of leisure sports in colleges and universities can help students to plan their spare time reasonably and can guide college students to exercise their bodies and promote their own all-round development.

\section{Significance of Developing Leisure Sports in Colleges and Universities}

\subsection{Create a good campus sports culture environment}

The construction of sports culture in universities can not only enrich the leisure life of college students, but also benefit the improvement of college campus culture construction. Leisure sports are a kind of activity with strong autonomy and arbitrariness. Therefore, colleges and universities should be organized and managed to some extent and to a certain extent. In this regard, our primary task is to establish a scientific concept of physical fitness, establish the guiding principle of health first, with all-round development of students as the core, and actively carry out physical education on campus, the concept of leisure and sports, leisure and body care Become a student's conscious [1]. In the construction of PE culture in colleges and universities, it is necessary to carry out effective system construction according to the characteristics of college students in different stages and the connotation of leisure sports because the system is a guarantee to create a good campus culture.

\subsection{Improve college students' learning quality and quality of life}

Through the development of leisure sports, college students often take part in physical exercises in their spare time, which can not only relieve their tension, facilitate the recovery of energy and physical strength, but also enhance their physique so that they are energetic, relax and relieve stress, 
So that the emotional catharsis, the tired body and mind to get a positive rest, thereby enhancing the efficiency of work and study, but also to improve the quality of life of college students, most colleges and universities are more rigorous arrangements for the course of the University, the task of the class compared to college students Heavy, in their fatigue state of awareness of participation in sports relatively weak [2]. However, unlike other sports, leisure sports can make the passive changes such as the idea of actively participating in college students contribute to the improvement of their quality of life.

\subsection{Promote the Quality Education in Colleges and Universities}

Quality education is the ultimate goal of education, which requires perfecting human nature, improving people's work, study and quality of life, so that people's integrity can be fully and coordinately developed. Physical education is an important part of college education, which emphasizes the impact of quality education on people [2]. As an important part of physical education, leisure sports not only have the function of physical fitness for college students, but also promote their physical development and intellectual development. Its form flexibility, autonomy of activity time and freedom of venue provide more free space for college students.

\section{Problems in Developing Leisure Sports in Colleges and Universities}

College students are in the heyday of their lives, their leisure activities are rich and colorful, not satisfied with the sports through physical education, they desire a wide range of activities and fulfilling life, in order to eliminate work, Study and life in a variety of pressures and distress. However, in practice, the development of leisure sports in colleges and universities is not satisfactory. Due to various reasons, it is not carried out or restricted, which is mainly reflected in the following aspects:

\subsection{Students leisure sports consciousness is weak}

Based on this background, most of the undergraduates tend to over-emphasize and emphasize scores in the process of education, neglecting their physical training. College students to strengthen physical exercise awareness is relatively weak, the lack of proper sports values, life-long physical exercise has not yet been formed concept. To some extent, they are accustomed to the kind of long time immersed in high school, studying hard and unconsciously going to physical exercise [2]. They always think that the university is a place of study rather than entertainment, and they regard physical exercise as a Wasting time sports, in physical education class, they are lazy to carry out various sports activities, only one purpose is to take credit, but not regarded as a way to enhance physical fitness.

\subsection{Colleges and universities to carry out sports activities in the form of a single project}

At present, the content of physical education in colleges and universities is still dominated by competitive sports, seldom the introduction of emerging leisure sports, sports events in addition to the ball or ball, the form of relatively simple, teaching content is relatively old and conservative, and often with Student test scores linked to a certain degree of compulsory, thus ignoring the interest in the training of students, leading to the students' passive participation [3].

\subsection{University sports project funding inadequate}

The limited sports funds and resources of colleges and universities only maintain the normal physical education classes of students, the training of high-level athletes and some high-level athletic programs. There are no excessive funds to support the development of leisure sports activities for college students. Most colleges and universities carry out leisure activities Physical activity only stays on the level of a college or department, which cannot attract more college students at all. And not all of the faculty members or faculty members are actively involved [3]. As a result, the gradual disappearance of college students' physical activity is in their spare time. Due to the lack of maintenance, all kinds of sports facilities in colleges and universities gradually become obsolete and scrapped, making the already scarce sports facilities scarce. 


\subsection{Professional teachers lack of skills}

The majority of college PE teachers' skills still remain in traditional projects such as basketball, soccer, badminton, table tennis, volleyball and martial arts. They seldom come into contact with recreational sports and lack the systematic training of physical education ability [3]. Few sports Professional teachers do not even know what sports are for leisure. In addition, at the school level, there are few opportunities for foreign exchange and further study in the field of leisure sports teaching, which greatly affects and restrains the development of leisure sports in colleges and universities.

\subsection{Imperfect management mechanism}

Most colleges and universities have not formulated the relevant rules and regulations to carry out leisure sports, lack of proper guidance measures, and the university leaders did not produce enough understanding of the benefits of leisure sports activities did not correctly view that college students should study hard, and later in the community to gain a foothold, and sports activities occasionally carried out on the line, sports too much to do a bit unsustainable, which will lead students not to form a leisure sports lifestyle, a serious obstacle to leisure sports in colleges and universities development [4] .

\subsection{A single teaching content, lack of leisure sports}

Under the influence of the traditional sports teaching, at present, the main contents of physical education in colleges and universities mainly focus on the study of sports technique, which often overlook the students' interest. Strong interest is to engage in cognitive activities based on the development of good habits are inseparable from the interest, the choice of teaching content without distinctions, it will lead to students not interested in sports, is not conducive to the realization of lifelong physical education. In my current teaching environment of PE, most of the institutions are based on the training of economic sports. The teaching programs are single and outdated [4]. Many students who are not good at physical education are offensive to sports, not to mention the idea of making them lifelong sports. And in many sports textbooks, there are still many traditional sports, boring content, and professional sports are more difficult, not suitable for leisure time. This will seriously delay the construction of leisure sports.

\section{Countermeasures of Developing Leisure Sports in Colleges and Universities}

\subsection{Strengthen the publicity of leisure sports in colleges and universities and raise their awareness of leisure sports}

In this regard, we can provide information on leisure sports to students through relevant sports lectures and sports commentary, and impart some knowledge of sports fitness and health care activities so as to broaden students' horizons and let more students understand sports and leisure [4]. To encourage and guide more students to participate in colorful and leisure sports activities and to stimulate their awareness of active participation in leisure and sports activities so that they will form a positive and enthusiastic sports lifestyle and are keen to devote themselves to health, civilization, science and leisure sports come.

\subsection{Pay attention to the cultivation of leisure sports professional teachers}

The key factor for professional physical education teachers to develop Leisure Physical Education in Colleges and Universities are the professional teachers' knowledge; personality and conduct play a crucial role for college students [5]. Therefore, in order to develop leisure and sports career in colleges and universities, it is necessary to strengthen the construction of teaching staff, introduce the talents specialized in leisure sports teaching to the teaching staff, and train professional teachers frequently, strengthen the external communication and create a superior external Environment allows teachers to study and improve their leisure sports theory and teaching level, not only to make them clear the importance of developing leisure sports in colleges and universities, but also to enable 
students to clear the importance of leisure sports in colleges and universities [5].

\subsection{Strengthen the guidance of leisure sports}

As leisure sports activities are widely carried out in colleges and universities, students' voices are getting stronger and stronger and their demands for sports are getting higher and higher. Therefore, as a university, should take positive and effective measures to correctly guide students to participate in various leisure activities [5]. However, whether leisure sports can achieve their value depends to a large extent on the attitude of university leaders. In this regard, the leaders of colleges and universities should change their thinking, should support and encourage leisure sports as much as possible and incorporate leisure sports into school sports work plans so as to ensure the smooth development of leisure sports. In the meantime, a concerted effort should be made to promote the participation of all students in recreational sports through the promotion of class, department or college as well as whole-school sports activities. In this regard, professional physical education teachers should always be concerned about and guidance class, Department of physical education cadres, to strengthen their basic knowledge of leisure sports and basic skills training, and constantly improve their professional quality and service capabilities, and strive to play their leisure sports activities [5]. The backbone of the role to ensure the smooth development of leisure sports activities.

\subsection{Increase efforts to improve the stadium facilities}

Education administration departments and university leaders should fully understand the importance of strengthening the construction of stadium and gymnasium facilities. For colleges and universities that have inadequate venues and facilities, they should try their best to increase investment in sports funds and construction of sports venues, purchase some new sports equipment if necessary. In response, colleges and universities should strengthen the rational use of sports facilities, open to students, in order to meet the majority of students to participate in recreational sports activities [6]. At the same time, it is also necessary to strengthen the management of stadiums and facilities. By extending the opening hours of sports venues, improving service awareness and using them appropriately, we can maximize the benefits and functions and promote the full implementation of leisure sports in colleges and universities. As an important component of lifelong physical education, college leisure sports attract more and more people's attention [6]. Therefore, our colleges and universities should adapt to the needs of society and the changes of individual students, incorporate leisure sports into the university education system, bring them into the life of college students and make them gradually become a healthy and happy life style.

\subsection{Optimize the teaching content, highlight the leisure of teaching}

Generally speaking, the physical education courses in colleges and universities are generally of a kind that students can choose according to their own interests. However, for the moment, colleges have fewer types of courses, a single content and lack of leisure. In order to enrich the content of physical education, it is necessary to highlight the leisure nature of sports. Therefore, we can increase sports, reduce the proportion of competitive sports [6]. You can add yoga, college sports dance, aerobics, tai chi and so can both exercise and leisure sports in the teaching. In addition, after all, the campus sports venues are limited, in which case you can choose the appropriate outdoor sports. In addition to meeting the needs of sports, outdoor venues also inspire students' love of nature.

\subsection{Improve the Teaching Mechanism of Leisure Sports in Colleges and Universities}

In promoting leisure sports in colleges and universities, we must establish a sound teaching mechanism. In the curriculum to increase the types of physical education for students to choose, select high quality teaching materials to students. You can also buy some online public courses on leisure sports for students to change look. In addition to classroom teaching, students can be assisted in setting up leisure-related sports associations and helping them to carry out community activities to promote leisure sports [7]. You can also organize some sports activities. For example, sports and cultural festival, to carry out leisure sports lectures. Only in this way can students develop good sports fun, can help them correctly understand leisure sports, so as to promote the construction of college 
leisure sports.

\subsection{Adhere to the people-oriented teaching philosophy}

To construct the leisure sports system in colleges and universities, we should first update the teaching philosophy, adhere to the "people-oriented" thinking, and insist on the construction of leisure sports for the purpose of experiencing sports fun and physical fitness [7]. Therefore, colleges and universities must change their teaching philosophy, to cultivate students 'exercise habits and sports interests as the target, to cultivate students' correct understanding of leisure sports and to guide them to arrange leisure time rationally. In teaching activities, students are the main body; this is no exception to physical education. In the teaching of recreational sports curriculum, teachers should face their leader status, combined with the interests of students teaching characteristics. In addition, colleges and universities should step up publicity such as conducting occasional lectures on the importance of recreational sports or publishing articles on recreational sports in their school newspapers to deepen their understanding of teachers and students [7]. This will enable both teachers and students to recognize the benefits of leisure sports, so as to promote the construction of leisure sports in colleges and universities.

\section{Conclusions}

With the further deepening of PE reform in colleges and universities, how to inspire teachers 'initiative and enthusiasm in teaching and learning and how to improve the students' learning consciousness are the keys to the reform. Novel, stylish, rich physical education curriculum resources, is to connect the two aspects of the link. To strengthen the theoretical and practical value analysis of physical education curriculum resources development in colleges and universities, it is an important factor that determines the smooth implementation of physical education curriculum reforms in colleges and universities those developing and utilizing physical education curriculum resources in colleges and universities reasonably and effectively. The development of physical education curriculum resources in universities can widen the field of physical education research, promote the development of physical education curriculum and campus physical culture, and promote the integration and development between physical education and social sports as well as competitive sports. It is conducive to promoting the professional development of PE teachers and promoting the development of students' personality.

\section{References}

[1] Ch. Li, College sports and leisure culture construction and research, Contemporary sports science and technology, 2016, vol.11, pp. 117-119.

[2] F.Q. Li, Analysis of the lack of teaching and college physical education teaching and construction, Human resources development, 2017, vol.6, 111-114.

[3] L. T. Han, on college sports teaching and its development, Knowledge guide, 2015, vol.13, pp. 77-77.

[4] J.F. Guo, Ordinary college students’ leisure sports development analysis, Inner Mongolia Sports Science and Technology, 2016, vol.4, pp. 60-631.

[5] H.L. Yang, Analysis of college physical education and leisure sports integration, Sports space, 2017, vol.7, pp. 84-85.

[6] L.Y. Hu, Status quo of college students recreational sports and sports health promotion, Sports Research, 2006, vol.8, pp.54-57.

[7] S.Zh. Hao, Colleges and universities sport leisure education content and methods of exploration, Science and Technology Advisory, 2006, vol.14, pp.32-35. 